\title{
Pengendalian Biaya dan Waktu dengan Metode Earned Value (Studi Kasus : Rancang dan Bangun Sistem Penyediaan Air Minum Kota Dumai 450 LPD Tahap 1A)
}

\author{
Edhi Pandu SUKMONO ${ }^{1}$, ZAINURI $^{*}$, Widya APRIANI ${ }^{1}$ \\ ${ }^{1}$ Prodi Teknik Sipil, Fakultas Teknik, Universitas Lancang Kuning, email : zainuri@unilak.ac.id
}

Sejarah artikel

Diserahkan:

30 Maret 2021 $\begin{array}{ll}\text { Diterima: } & \text { 28 April } 2021 \\ \text { Tersedia online: } & 31 \text { Mei } 2021\end{array}$

\begin{abstract}
The Design and Build Project of Water Supply System for Dumai City 450 LPD Phase 1A was planned to be completed in 8 months. The performance in August 2020 was only 87.66\%, while the plan was at $100 \%$. There was a deviation of $-12.34 \%$, and therefore it is necessary to control the time delays and costs needed until the project can be completed. The purpose of this research is to control costs and time. This research uses the Earned Value method using Microsoft Project 2016. The results of the research in August 2020 show that the costs incurred are IDR 76,494,086,618.00, this value is smaller than the planned costs of IDR 77,168,849,034.00. The CPI value is obtained at 1.01 > 1, which indicates that the costs incurred are smaller. However, there was a delay in the project. This was also proven by the SPI value of $0.88<1$. There was a delay of 60 days along with a total fine of Rp. 249,224,093.00. So it is very important to do acceleration so that the project can be completed at the agreed time.
\end{abstract}

Keywords: cost, cpi, earned value, spi, time

\begin{abstract}
Abstrak
Proyek Rancang dan Bangun Sistem Penyediaan Air Minum Kota Dumai 450 LPD Tahap 1A direncanakan selesai dalam waktu 8 bulan. Kinerja bulan Agustus 2020 hanya 87,66\%, sedangkan rencana $100 \%$, terjadi deviasi sebesar $-12,34 \%$, maka diperlukan pengendalian waktu keterlambatan dan biaya yang dibutuhkan hingga proyek dapat terselesaikan. Tujuan penelitian ini untuk melakukan pengendalian biaya dan waktu. Penelitian ini menggunakan metode Earned Value dibantu dengan Microsoft Project 2016. Hasil penelitian bulan Agustus 2020 menunjukkan biaya yang telah dikeluarkan sebesar $R p$ 76.494.086.618,00 dimana nilai ini lebih kecil dibandingkan biaya rencana sebesar Rp 77.168.849.034,00. Nilai CPI diperoleh sebesar 1,01 > 1, yang menunjukkan bahwa biaya yang dikeluarkan lebih kecil. Namun terjadi keterlambatan pada proyek. Ini juga dibuktikan dengan nilai SPI 0,88 < 1, dimana didapatkan keterlambatan selama 60 hari beserta total denda sebesar Rp 249.224.093,00. Sangat penting dilakukan percepatan agar proyek dapat selesai pada waktu yang disepakati.
\end{abstract}

Kata kunci: biaya, cpi, earned value, spi, waktu

\section{Pendahuluan}

Dumai adalah kotamadya dengan jumlah penduduk 303.292 jiwa berdasarkan data BPS Provinsi Riau tahun 2019. Letak geografis Kota Dumai dipinggir laut dan gambut menimbulkan masalah air bersih layak konsumsi. Mengingat pentingnya peran dan fungsi dari air minum, maka pemerintah Kota Dumai berencana membangun konstruksi Sistem Penyediaan Air Minum (SPAM) berkapasitas 450 liter per detik guna memasok air bersih 
untuk 20.300 sambungan rumah atau setara dengan 101.500 jiwa di empat kecamatan Kota Dumai. Lokasi Proyek Rancang dan Bangun Sistem Penyediaan Air Minum Kota Dumai Kapasitas 450 LPD tahap 1A berada di Jalan Gatot Subroto, km 9, Bukit Timah, Kota Dumai. Proyek ini direncanakan dengan anggaran dana yaitu sebesar Rp. 77.168.849.034,05 dengan Nomor Kontrak Proyek 001/perjanjian/DTP/XII/ 2019. Proyek adalah suatu susunan pelaksanaan pekerjaan dengan kurun waktu yang ditentukan yang bertujuan untuk tercapainya suatu kegiatan dengan memanfaatkan sumber daya yang ada (Kartikasari, 2014). Proyek yaitu sebuah kegiatan yang terstruktur, terbatas dengan waktu, biaya yang ditentukan, tidak dilakukan secara terus menerus, serta spesifikasi untuk konsumen (Bakhtiyar, 2012).

Proyek dimaksud mulai dikerjakan tanggal 20 Desember 2019 dengan waktu pelaksanaan 180 hari kalender dan seharusnya berakhir pada 14 Juni 2020. Bulan Mei dan Juni pekerjaan di lapangan dihentikan total karena berbagai masalah yang diakibatkan dari pandemik Covid19 dengan diberlakukan Pembatasan Sosial Berskala Besar (PSBB), sehingga proses pengiriman material seperti pipa HDPE (High Density Polyethylene), Pipa GIP (Galvanized Iron Pipe), Material Bahan IPA 450, dan aksesoris pipa saluran yang dikirim dari luar daerah seperti Jakarta menjadi terhambat. Pemberhentian pekerjaan seperti ini dianggap Force Majeure sehingga tidak diperhitungkan sebagai keterlambatan. Waktu pelaksanaan proyek bertambah menjadi delapan bulan. Pekerjaan dilanjutkan pada bulan Juli dan diharapkan selesai pada bulan Agustus. Dengan demikian waktu pelaksanaan proyek menjadi 240 hari.

Prestasi yang dicapai proyek pada bulan Juli 2020 baru terealisasi $72,87 \%$, sedangkan prestasi rencana seharusnya yang dicapai yaitu $87,44 \%$, sehingga proyek ini mengalami deviasi yaitu sebesar $-14,57 \%$. Pada bulan Agustus 2020, prestasi proyek baru terealisasi $87,66 \%$, sedangkan prestasi seharusnya yang dicapai yaitu $100 \%$, sehingga terdapat deviasi sebesar $-12,34 \%$. Keterlambatan ini menyebabkan manajemen proyek harus segera melakukan pengendalian (Ismael, 2013). Manajemen proyek meliputi beberapa kegiatan penting mulai dari perencanaan, lalu tindakan pengorganisasian dan pengendalian sumber daya. Tindakan pengendalian yang diperlukan merupakan usaha yang disusun secara sistematis dalam menentukan standar yang selaras dengan sasaran dari perencanaan serta merencanakan sistem informasi, juga membandingkan progres pekerjaan sesuai yang disusun sebelumnya (Walean, 2012). Jika ditemukan suatu penyimpangan antara yang dilapangan dan ketentuan maka mengambil tindakan untuk memperbaiki secara efektif dan efisien agar capaian hasil sesuai dengan rencana (Pertiwi, 2018).

Dalam pelaksanaan proyek konstruksi, keterlambatan sering terjadi. Penyebab keterlambatan tersebut beragam. Misalnya hasil dari penelitian Tristania dan Nursin (2019) yang menunjukkan bahwa pada pekerjaan Jembatan Anak CBL Cibitung - Cilincing Seksi II, nilai Schedule Varians (SV) pada minggu ke-52 yaitu Rp 688.886,00 sampai minggu ke-55 adalah positif (+) dan dari minggu ke-56 sampai minggu ke-85 negatif (-). Saat peninjauan minggu ke-85 nilai schedule performance index (SPI) adalah 0,942 yang berarti kinerja pelaksanaan terjadi keterlambatan dari rencana.

Keterlambatan progres proyek merupakan hal yang tidak diinginkan, sebab dapat merugikan pihak-pihak terkait dari segi biaya maupun waktu (Suherman, 2016). Biaya proyek terdiri dari biaya langsung dan biaya tidak langsung (Nuswantoro, 2019). Biaya langsung meliputi biaya bahan, upah tenaga kerja, peralatan, subkontraktor dan biaya lainnya. Biaya tidak langsung merupakan biaya yang dibebankan pada proyek namun bukan merupakan kegiatan utama proyek seperti biaya pemasaran, overhead kantor pusat dan cabang yang tidak berhubungan langsung dengan pelaksanaan proyek (Nurdiana, 2015). Keterlambatan dapat menyebabkan pembengkakkan biaya. Menurut Rahman (2010), biaya sub kontraktor merupakan biaya terbesar, mencapai $85 \%$ dari total biaya proyek. Dengan demikian item biaya tersebut harus dicermati. Dengan bekerja pada masa denda, maka diperlukan pengendalian proyek yang lebih agresif agar proyek selesai sesuai target dan tidak dibutuhkan biaya tambahan lagi (Khinasih, 2018). Berdasarkan permasalahan yang terjadi diperlukan 
adanya suatu upaya dalam pengendalian waktu dan biaya pelaksanaan proyek dengan menggunakan metode earned value concept.

\section{Metodologi}

\section{Lokasi Penelitian}

Lokasi penelitian yang digunakan dalam studi ini adalah tempat dimana Proyek Rancang dan Bangun Sistem Penyediaan Air Minum (SPAM) Dumai Kapasitas 450 LPD tahap 1A dilaksanakan. Proyek dimaksud akan memasok air minum bagi masyarakat di Kota Dumai. Lokasi proyek dapat dilihat pada Gambar 1.

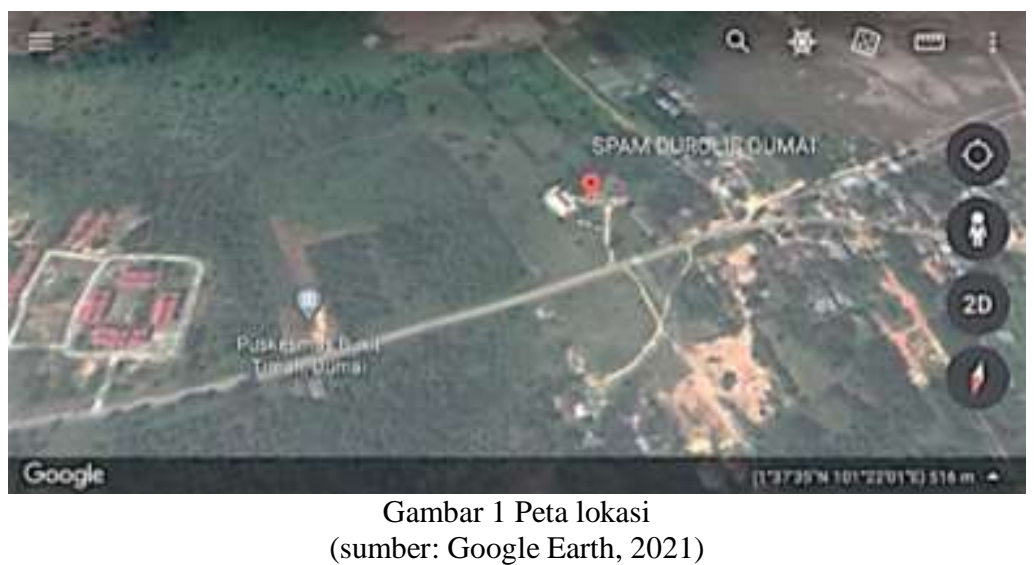

\section{Pengumpulan Data}

Data yang dikumpulkan terdiri atas data primer yang merupakan data mentah yang belum diolah dan data sekunder yang berasal dari pengolah data lainnya seperti data statistik, catatan keuangan, catatan progres pekerjaan dan lain-lain. Data tersebut dikumpulkan dari pihak terkait langsung dengan proyek.

\section{Teknik Pengumpulan Data}

Data-data dikumpulkan langsung dari lapangan. Informasi dan berkas yang menjadi data penelitian diperoleh dari PT. Adhi Karya (Persero) Tbk. Data primer diperoleh dengan cara melakukan wawancara bersama Project Manager, Project Engineering Manager, serta pengawas di lapangan pada proyek Rancang dan Bangun Sistem Penyediaan Air Minum Kota Dumai Kapasitas 450 LPD Tahap 1A.

Selain melakukan wawancara, cara yang digunakan untuk mengumpulkan data sekunder dengan mengumpulkan salinan berkas dari pihak terkait. Data yang diperlukan adalah :

- Time schedule (kurva S)

- Laporan progress bulanan

- Rencana Anggaran Biaya (RAB)

Data umum proyek yang diperoleh dari pihak terkait terlihat pada Tabel 1.

Tabel 1 Data umum proyek

\begin{tabular}{|l|l|}
\hline Nama Proyek & $\begin{array}{l}\text { Rancang dan Bangun Sistem Penyediaan Air Minum Kota Dumai Kapasitas 450 } \\
\text { LPD Tahap 1A }\end{array}$ \\
\hline Nilai Pekerjaan & Rp. 77.168.849.034,05 \\
\hline Alamat & Jalan Gatot Subroto, Dumai Barat, Kota Dumai, Provinsi Riau \\
\hline Waktu Pelaksanaan & $\begin{array}{c}\text { 180 Hari Kalender } \\
60 \text { Hari Kalender (Force Majeure) } \\
60 \text { Hari Kalender (Addendum) }\end{array}$ \\
\hline Pemilik Proyek & PT. Dumai Tirta Persada \\
\hline Konsultan Pengawas & PT. Arkonin \\
\hline Kontraktor Pelaksana & PT. Adhi Karya (Persero), Tbk \\
\hline
\end{tabular}




\section{Earned Value Concept}

Earned value concept atau dikenal dengan konsep nilai hasil yang memperhitungkan progres pekerjaan yang dituntaskan sesuai estimasi waktu yang direncanakan dalam anggaran biaya (Abma, 2016). Konsep nilai hasil menggunakan 3 indikator sebagai analisa kinerja dan memperkirakan waktu yang akan dicapai (Yusdiana \& Satyawisudarini, 2018). Ketiga indikator tersebut adalah ACWP (Actual Cost of Work Performed), BCWS (Budgeted Cost of Work Scheduled) dan BCWP (Budgeted Cost of Work Performed) (Milah, 2020).

Dalam menilai kemajuan pekerjaan atau menilai kinerja suatu proyek dapat ditentukan dari beberapa faktor (Milah, 2020), yaitu berdasarkan nilai varian jadwal (SV/Schedule Varians) dan varian biaya (CV/Cost Varians); perbedaan antara varian dengan standar angka yang terpantau; produktivitas dan kinerja; perkiraan anggaran biaya yang masih dibutuhkan untuk menyelesaikan proyek. Bila diperoleh hasil CV negatif, dapat dikatakan bahwa biaya yang digunakan untuk menyelesaikan proyek lebih besar dari dianggarkan sebelumnya. Bila nilai SV didapat hasil negatif, menunjukkan bahwa suatu proyek tersebut mengalami keterlambatan dari jadwal perencanaan.

Kinerja proyek dapat dilihat dari angka indeks yang diperoleh terdiri dari Indeks Kinerja Biaya/Cost Performance Indeks (CPI) dan Indeks Kinerja Jadwal/Schedule Performance Indeks (SPI). Angka indeks yang diharapkan lebih besar dari 1 yang artinya, bila CPI > 1 berarti pengeluaran real lebih kecil dari anggaran dan bila SPI > 1 memperlihatkan bahwa pekerjaan lebih cepat dari waktu yang direncanakan. Apabila nilai indeks yang diperoleh kurang dari 1 maka dapat dikatakan bahwa telah terjadi keterlambatan dan biaya yang digunakan telah melebihi anggaran.

\section{Analisis Data}

Data-data yang diperoleh dari pihak-pihak terkait dikumpulkan, kemudian dilakukan pengolahan terhadap data-data tersebut dan dianalisis. Beberapa langkah yang dilakukan untuk menganalisis data yang terkumpul menggunakan formulasi sebagai berikut (Husen A., 2011) :

- Analisis BCWS (Budgeted Cost Of Work Schedule) $\mathrm{BCWS}=\%$ Progres Rencana $\mathrm{x}$ Nilai Proyek

- Analisis BCWP (Budgeted Cost Of Work Performanced) $\mathrm{BCWP}=\%$ Progres Aktual $\mathrm{x}$ Nilai Proyek

- Analisis ACWP (Actual Cost for Work Performed) $\mathrm{ACWP}=$ Biaya langsung + Biaya tidak langsung

- Cost Variance (CV) $\mathrm{CV}=\mathrm{BCWP}-\mathrm{ACWP}$

- Cost Performance Index (CPI) $\mathrm{CPI}=\frac{\mathrm{BCWP}}{\mathrm{ACWP}}$

- Estimated Completion Date (ECD) $=\left(\frac{\text { Sisa Waktu }}{\text { SPI }}\right)+$ WaktuTerpakai

- Schedule Variance (SV) $\mathrm{SV}=\mathrm{BCWP}-\mathrm{BCWS}$

- Schedule Performance Index (SPI) SPI $=\frac{\text { BCWP }}{\mathrm{BCWS}}$

- Estimated at Completion (EAC) $=\left(\frac{\text { Sisa Anggaran }}{\text { CPI }}\right)+$ ACWP 


$$
=\left(\frac{\text { Total Anggaran }-\mathrm{BCWP}}{\mathrm{CPI}}\right)+\mathrm{ACWP}
$$

- Presentase keterlambatan atau percepatan

$$
=\frac{(100 \%-\text { ECD })}{(\text { Jadwal Rencana x 100\%) }}
$$

- Presentase biaya penambahan atau penurunan biaya aktual terhadap biaya yang dianggarkan.

$=\frac{100 \%-\mathrm{EAC}}{\text { Total Biaya } \times 100 \%}$

- $\quad$ Sisa Anggaran = BAC-EAC

\section{Hasil}

\section{Hasil Penelitian}

Durasi pelaksanaan proyek Rancang dan Bangun Sistem Penyediaan Air Minum 450 LPD Kota Dumai Tahap 1A yaitu 180 (seratus delapan puluh) hari kalender dengan nilai kontrak Rp 77.168.849.034,05. Adanya pekerjaan tambah dan kurang atau Contract Change Order (CCO) dan dianggap mampu untuk menyelesaikan, maka kontraktor mendapatkan kesempatan bekerja pada masa denda sebesar $1 / 1000 \mathrm{x}$ sisa pekerjaan per hari.

\begin{tabular}{|c|c|c|}
\hline No. & Uraian Pekerjaan & Jumlah Harga \\
\hline \multicolumn{3}{|c|}{ Pekerjaan Tahap 1A } \\
\hline I & Pekerjaan Intake & Rp 9.673.864.662 \\
\hline II & Pekerjaan Instalasi Pengolahan Air (IPA) & Rp 37.380.765.521 \\
\hline III & Pekerjaan Reservoir Booster & Rp 3.125.547.300 \\
\hline IV & Pekerjaan Pipa Transmisi dan Distribusi & Rp 11.500.040.350 \\
\hline $\mathrm{V}$ & Rekondisi Jalan dan Utilitas Umum & Rp 8.498.328.200 \\
\hline VI & Pekerjaan Jembatan Pipa dan Perlintasan Saluran & Rp 4.256.903.000 \\
\hline VII & Pekerjaan DED dan Perijinan & Rp 2.733.400.000 \\
\hline \multicolumn{2}{|c|}{ Total Pekerjaan } & Rp 77.168.849.034 \\
\hline \multicolumn{2}{|c|}{ PPN $10 \%$} & Rp 7.716.884.903 \\
\hline \multicolumn{2}{|c|}{ Jumlah Total Termasuk PPN 10\% } & Rp 84.885.733.900 \\
\hline \multicolumn{2}{|c|}{ Dibulatkan } & Rp 84.885.734.000 \\
\hline
\end{tabular}

Tabel 2 Rekapitulasi Rencana Anggaran Biaya

(Sumber : PT. Adhi Karya (Persero), Tbk., 2020)

Tabel 3 Rekapitulasi laporan deviasi

\begin{tabular}{|l|c|c|c|}
\hline \multicolumn{1}{|c|}{ Bulan } & Kumulatif Rencana (\%) & Kumulatif Realisasi (\%) & Deviasi (\%) \\
\hline Juni 2020 & 70,12 & 56,56 & $-13,56$ \\
\hline Juli 2020 & 87,44 & 72,87 & $-14,57$ \\
\hline Agustus 2020 & 100,00 & 87,66 & $-12,34$ \\
\hline
\end{tabular}

(Sumber : PT. Adhi Karya (Persero), Tbk., 2020)

Setelah menelaah laporan progres pekerjaan antara rencana dan realisasi serta meninjau catatan keuangan dari pihak pelaksana proyek, terdapat perbedaan yang cukup besar. Perbedaan waktu terjadi merupakan deviasi yang harus dicermati. Deviasi antara bobot realisasi lapangan dan bobot rencana bulan Juni 2020 yaitu $-13,56 \%$, deviasi bobot pada bulan Juli 2020 yaitu -14,57\%. Deviasi bobot pekerjaan pada bulan Agustus 2020 yaitu - 
12,34. Penyimpangan yang dialami pada waktu pekerjaan berpengaruh terhadap biaya proyek yang dimaksud.

\section{Hasil Earned Value}

Earned Value yang ditinjau untuk melihat nilai hasil yang dicapai menggunakan progres pelaksanaan proyek pada bulan Agustus. Langkah-langkah perhitungan yang dilakukan adalah sebagai berikut :

- Perhitungan Budgeted Cost of Work Schedule (BCWS)

Pekerjaan pada bulan Agustus 2020 :

BCWS Agustus = Bobot BCWS $\mathrm{x}$ Total Anggaran Proyek (BAC)

$=100 \% \times \mathrm{Rp} 77.168 .849 .034,00$

$=\operatorname{Rp} 77.168 .849 .034,00$

Nilai yang harusnya dicapai pada bulan Agustus 2020 sebesar Rp 77.168.849.034,00.

Nilai ini sesuai dengan perhitungan dalam anggaran atau rencana pelaksanaan proyek.

- Perhitungan Budgeted Cost of Work Performed (BCWP)

Pekerjaan pada bulan Agustus 2020 :

BCWP Agustus = Bobot BCWP x Total Anggaran Proyek $(\mathrm{BAC})$

$=87,66 \% \times \mathrm{Rp} 77.168 .849 .034,00$

$=\operatorname{Rp} 67.646 .213 .063,00$

Nilai capaian pada bulan Agustus 2020 berada di bawah anggaran yang direncanakan yaitu sebesar Rp 67.646.213.063,00. Capaian ini masih di bawah target yang harusnya dicapai oleh pelaksanaan proyek.

- Perhitungan Schedule Varians (SV)

Schedule Varians (SV) bulan Agustus 2020 :

SV Agustus $\quad=$ BCWP Agustus - BCWS Agustus

$=\operatorname{Rp} 67.646 .213 .063,00-\operatorname{Rp} 77.168 .849 .034,00$

$=-\operatorname{Rp} 9.522 .635 .971,00$

Terjadi perbedaan antara realisasi dan rencana menyebabkan adanya selisih dengan nilai Rp 9.522.635.971,00. Ini mengindekasikan bahwa proyek tersebut terlambat dari waktu yang disepakati.

- Perhitungan Cost Varians (CV)

Biaya langsung dan tidak langsung adalah ACWP Agustus Rp 67.054.716.329,00 berdasarkan catatan aktual kontraktor.

Cost Varians (CV) bulan Agustus 2020

$\mathrm{CV}$ Agustus $\quad=$ BCWP Agustus - ACWP Agustus

$=\operatorname{Rp} 67.646 .213 .063,00-\operatorname{Rp} 67.054 .716 .329,00$

$=\operatorname{Rp} 591.496 .734,00$

Capaian pekerjaan dengan perkiraan biaya sebesar Rp 67.646.213.063,00 dengan biaya aktual yang dikeluarkan sebesar Rp 591.496.734,00 memperlihatkan bahwa pelaksanaan masih menyisakan sejumlah dana untuk menyelesaikan pekerjaan tersebut.

- Schedule Performance Index (SPI) bulan Agustus 2020

$$
\begin{aligned}
\text { SPI Agustus } & =\frac{\text { BCWP Agustus }}{\text { BCWS Agustus }} \\
& =\frac{\operatorname{Rp~67.646.213.063,00~}}{\operatorname{Rp~77.168.849.034,00}} \\
& =0,88
\end{aligned}
$$

Indeks capaian terhadap waktu pelaksanaan proyek di bawah yang seharusnya dicapai, hanya $88 \%$ dari $100 \%$ yang seharusnya. Dengan demikian pelaksanaan proyek tersebut dinyatakan terlambat. 
- Cost Performance Index (CPI) bulan Agustus 2020

CPI Agustus

$$
\begin{aligned}
& =\frac{\text { BCWP Agustus }}{\text { ACWP Agustus }} \\
& =\frac{\operatorname{Rp~67.646.213.063,00~}}{\operatorname{Rp~67.054.716.329,00~}} \\
& =1,01
\end{aligned}
$$

Dari segi biaya, terlihat bahwa pekerjaan tersebut telah melebihi anggaran dengan nilai capaian sebesar 1,01. Dengan kondisi seperti ini pelaksana proyek terancam rugi.

- Estimated Completion Date (ECD) bulan Agustus 2020

$$
\begin{aligned}
\text { Waktu kontrak } & =8 \text { bulan } \\
\text { Adendum } & =2 \text { bulan }(60 \text { hari }) \\
\text { Total waktu tersedia } & =10 \text { bulan } \\
\text { ECD Agustus } & =\frac{\text { (Sisa Waktu) }}{\text { SPI }}+\text { Waktu Terpakai } \\
& =\frac{(2 \text { bulan })}{0,88}+8 \text { bulan } \\
& =10,27 \text { bulan } \\
& =\text { Total Waktu }- \text { ECD Agustus } \\
& =10 \text { bulan }-10,27 \text { bulan } \\
& =-0,27 \text { bulan (terlambat selama } 8 \text { hari })
\end{aligned}
$$

Perpanjangan waktu adalah 60 hari (2 bulan)

- Estimated at Completion (EAC) bulan Agustus 2020

$$
\begin{aligned}
\text { EAC Agustus } & =\frac{(\text { Total Anggaran - BCWP })}{C P I}+\text { ACWP } \\
& =\frac{(\operatorname{Rp~77.168.849.034,00-~Rp~67.646.213.063,00)~}}{1,01}+\operatorname{Rp~67.054.716.329,00~} \\
& =\operatorname{Rp~76.494.086.618,00~}
\end{aligned}
$$

Estimasi biaya yang dibutuhkan untuk seluruh pekerjaan sebesar Rp 76.494.086.618,00 dengan kondisi terkini.

- Total Biaya Denda

Total sisa item pekerjaan Proyek SPAM Dumai Tahap 1A adalah sebagai berikut :

$$
\begin{array}{llr}
\text { IPA Kapasitas 50 LPS } & =\mathrm{Rp} & 1.578 .634 .100,00 \\
\text { Bangunan Reservoir 1000 m } & =\mathrm{Rp} & 865.237 .900,00 \\
\text { Landscape Reservoir Booster } & =\mathrm{Rp} & 723.086 .400,00 \\
\text { Casing Pipa GIP-Crossing Jalan } & =\mathrm{Rp} & 673.250 .600,00 \\
\text { Perlintasan Saluran } & =\mathrm{Rp} & 313.525 .880,00 \\
\cline { 2 - 3 } & =\mathrm{Rp} & 4.153 .734 .880,00
\end{array}
$$

Total Biaya Denda $=\frac{1}{1000} \times \operatorname{Rp} 4.153 .734 .880,00 \times 60$ hari

$$
\begin{aligned}
\text { EAC Denda } & =\text { EAC Agustus }+ \text { Total Biaya Denda } \\
& =\operatorname{Rp~76.494.086.618,00+Rp~249.224.093,00~} \\
& =\operatorname{Rp} 76.743 .310 .710,00
\end{aligned}
$$

- Sisa Anggaran

Sisa anggaran

$$
\begin{aligned}
& =\mathrm{BAC}-\text { EAC Denda } \\
& =\operatorname{Rp} 77.168 .849 .034,00-\operatorname{Rp} 76.743 .310 .710,00 \\
& =\operatorname{Rp} 425.538 .324,00
\end{aligned}
$$

Dengan tambahan waktu pekerjaan selama 60 hari (sesuai adendum) diperkirakan pelaksana proyek harus menyediakan dana untuk biaya denda sebesar Rp 249.224.093,00.

Sebagai perbandingan kondisi pelaksanaan proyek selama 3 bulan terakhir yaitu bulan Juni, Juli dan Agustus dapat dilihat pada Tabel 4 berikut ini. 
JURNAL REKAYASA KONSTRUKSI MEKANIKA SIPIL (JRKMS)

Volume 04 Nomor 01 Mei 2021

p-ISSN 2614-5707 e-ISSN 2715-1581

Tabel 4 Rekapitulasi laporan analisis Hasil Earned Value bulan Juni 2020 - Agustus 2020

\begin{tabular}{|c|c|c|c|}
\hline Indikator & Juni 2020 & Juli 2020 & Agustus 2020 \\
\hline BCWS & Rp 54.110.796.943 & Rp 67.476.441.595 & Rp 77.168.849.034 \\
\hline BCWP & $\mathrm{Rp} 43.646 .701 .014$ & Rp 56.232.940.291 & Rp 67.646.213.063 \\
\hline ACWP & Rp 37.812.604.827 & Rp 49.148.036.758 & Rp 67.054.716.329 \\
\hline SV & -Rp 10.464.095.929 & -Rp 10.464.095.929 & -Rp 9.522.635.971 \\
\hline $\mathrm{CV}$ & Rp 5.834.096.187 & Rp 7.084.903.533 & Rp 591.496.734 \\
\hline SPI & 0,81 & 0,83 & 0,88 \\
\hline CPI & 1,15 & 1,14 & 1,01 \\
\hline ECD & 9,48 & 9,20 & 10,27 \\
\hline EAC & Rp 66.853.968.930 & Rp 67.446.187.399 & Rp 76.494.086.618 \\
\hline
\end{tabular}

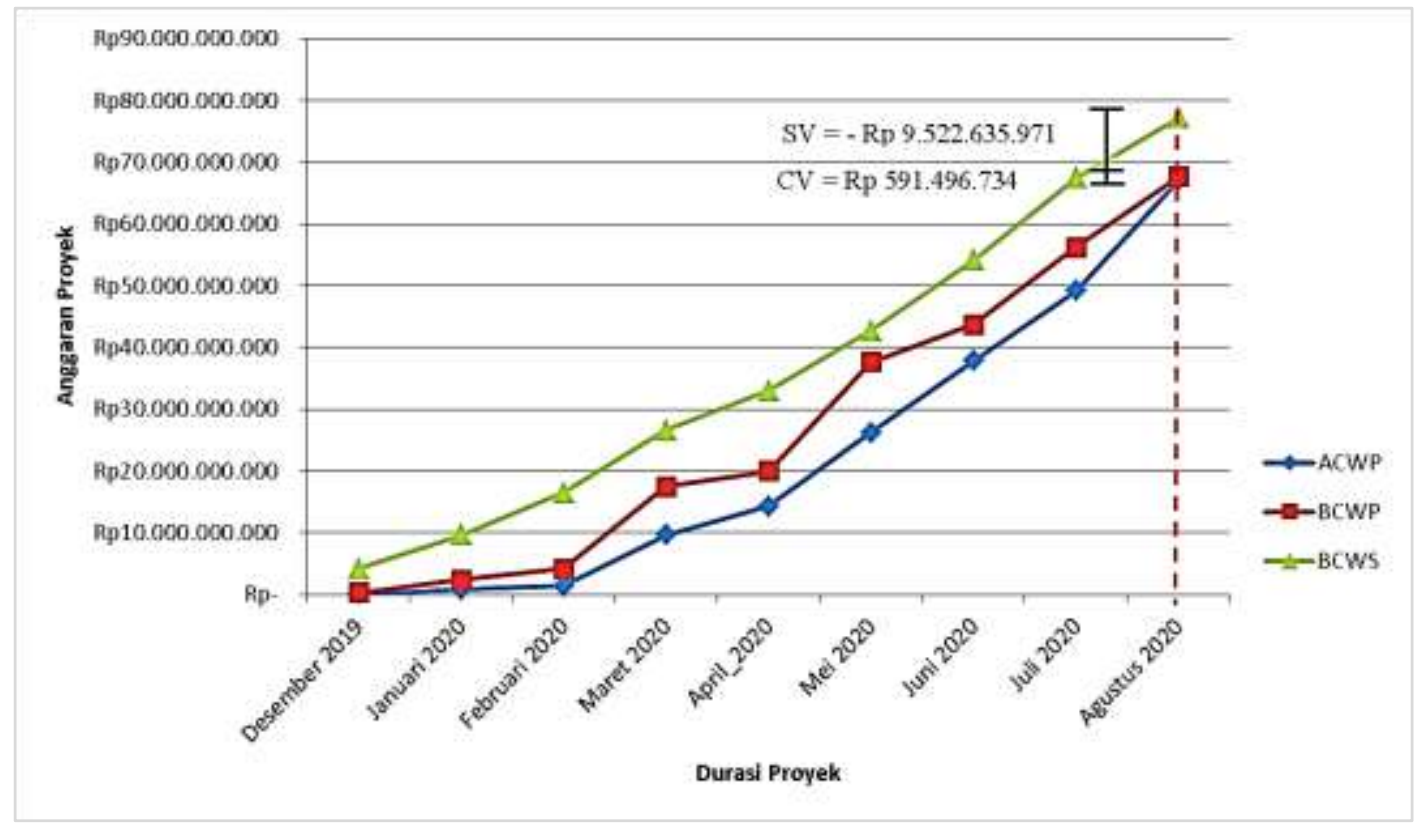

Gambar 2 Grafik analisis variance

Analisis grafik varians pada Gambar 2 memperlihatkan bahwa progres pekerjaan sejak awal mengindikasikan keterlambatan. Pada bulan kedua keterlambatan tersebut sudah terlihat nyata. Keterlambatan terus terjadi pada bulan-bulan selanjutnya dan hingga batas waktu yang disepakati pelaksanaan pekerjaan belum mencapai progres $100 \%$ sehingga membutuhkan tambahan waktu selama 60 hari.

\section{Pembahasan}

Hasil penelitian ini, yang meneliti pelaksanaan proyek SPAM (Sistem Penyediaan Air Minum) di kota Dumai juga terjadi keterlambatan sehingga membutuhkan tambahan waktu selama 2 bulan (60 hari). Tambahan waktu tersebut disertai dengan denda sebesar 1/1000 perhari. Keterlambatan tersebut disebabkan oleh pembatasan yang diberlakukan karena kondisi negara menghadapi pandemi Covid-19. Pembatasan perkumpulan orang-orang dalam skala besar menyebabkan pekerjaan dilakukan lebih lambat dari yang diperkirakan.

Masih berhubungan dengan pandemi Covid-19, sebagian pengiriman barang dari luar daerah juga menemukan hambatan. Material datangan tersebut terlambat sampai di lokasi prooyek. Keterlambatan mempengaruhi pekerjaan dilapangan yang membutuhkan material tersebut. Kondisi ini juga berdampak pada pekerjaan lainnya yang baru dapat dimulai setelah pekerjaan yang membutuhkan material datangan selesai dikerjakan. Dampak PSPB terjadi 
penghentian sementara pekerjaan sebagai kondisi mendesak (force majeure) selama dua bulan. Penghentian seperti itu tidak diperhitungkan sebagai hari kerja namun waktu penyelesaian proyek semakin panjang.

Penambahan waktu kerja selama 2 bulan (60 hari) diharapkan dapat mengatasi masalah terbengkalainya proyek. Meskipun dalam perhitungan pelaksanaan proyek dapat dikatakan bahwa pelaksana tidak mengalami kerugian secara finasial namun keterlambatan tersebut benar-benar menguras keuntungan yang diprediksi sebelumnya. Apabila waktu yang diberikan tidak dimanfaatkan sebaik-baiknya maka sangat besar kemungkinannya pelaksana proyek mengalami kerugian dari sisi finasial dan nama baik.

Keterlambatan penyelesaian proyek konstruksi juga terjadi pada proyek lainnya. Penelitian lain yang juga menemukan keterlambatan dalam pelaksanaan proyek konstruksi adalah yang dilakukan (Abma, V., 2016).) pada pembangunan Hotel Fave di Kota Baru, Yogyakarta. Telaah dilakukan menggunakan metode Earned Value dan ditemukan bahwa mulai dari minggu 25-28 semua bernilai negatif. Nilai negatif tersebut mengidentifikasikan bahwa pelaksanaan proyek tersebut berjalan lambat dari jadwal yang ditentukan. Nilai SPI pada tinjauan bulan ke-7 (minggu ke 25-28) sebesar 0,63 $<1$. Hasil tersebut memperlihatkan bahwa kinerja waktu pelaksanaan proyek berjalan lambat dari rencana awal. Hasil analisis pengendalian waktu menunjukkan bahwa proyek yang dimaksud mengalami keterlambatan yang sangat besar dan perlunya dilakukan perencanaan jadwal ulang.

Proyek Rancang dan Bangun Sistem Penyediaan Air Minum 450 LPD Kota Dumai Tahap 1A yang diteliti, meskipun mengalami keterlambatan penyelesaian, namun pada biaya tambahan yang dibutuhkan masih di bawah estimasi. Kontraktor tidak mengalami kerugian secara finansial hanya target keuntungan yang telah diperhitungkan tidak tercapai. Kondisi ini berbeda dengan hasil penelitian (Kartikasari, D., 2014) yang dilakukan pada proyek Struktur dan Arsitektur Production Hall-02 Pandaan menggunakan metode Earned Value melalui parameter dilakukan estimasi pada biaya dan waktu diperoleh hasil Cost Variance (CV) -Rp 738.219.033,00 dengan nilai negatif, menunjukkan bahwa biaya yang digunakan untuk penyelesaian proyek tersebut lebih besar dari perencanaan. Kemudian dilakukan analisa percepatan dengan lintasan kritis pekerjaan. Pada minggu ke-14 dianalisis. Hasil analisis data diperoleh nilai akhir dan penyelesaian waktu pekerjaan selama 170 hari. Keterlambatan pelaksanaan proyek akan mempengaruhi kinerja biaya. Bila biaya melebihi estimasi maka dapat dikatakan proyek tersebut merugi.

Contoh lain proyek konstruksi yang mengalami masalah finansial adalah hasil penelitian (Messah, 2013), pada penelitian pekerjaan konstruksi Embung Irigasi Oenaem, Kabupaten Timor Tengah Utara, diperoleh nilai cost performance index (CPI) 0,9, yang menunjukkan CPI $<1$ yang berarti bahwa actual cost (AC) lebih besar dari pekerjaan yang dilaksanakan.

Meskipun keterlambatan penyelesaian proyek konstruksi dapat terjadi dimana pun, namun langkah bijak yang harus dilakukan adalah melakukan pengawasan ketat dan jika terjadi keterlambatan harus segera ditemukan solusi untuk mengatasinya. Dengan kata lain, jangan membiarkan keterlambatan terjadi tanpa ada solusi untuk segera memperbaikinya.

\section{Kesimpulan}

Setelah dilakukan analisis terhadap data-data yang diperoleh, maka dapat disimpulkan sebagai berikut :

- Berdasarkan perhitungan, prestasi kemajuan pekerjaan, Schedule Performance Index didapat angka 0,88 yang menunjukkan SPI $<1$, yang berarti pekerjaan mengalami keterlambatan dari perencanaan awal. Cost Performance Index (CPI) didapat angka 1,01 yang menunjukkan CPI > 1 nilai ini berarti pengeluaran lebih kecil dari anggaran yang direncanakan.

- Berdasarkan perhitungan estimasi biaya untuk penyelesaian proyek (EAC) Rp 76.494.086.618,00 dan ditambah dengan denda selama 60 hari sebesar Rp 
249.224.093,00 sehingga total anggaran yang dibutuhkan untuk menyelesaikan proyek adalah Rp 76.743.310.710,00 ini menunjukkan bahwa biaya yang dibutuhkan untuk menyelesaikan proyek lebih kecil dari anggaran yang direncanakan yaitu sebesar $\mathrm{Rp}$ 77.168.849.034,00 dari nilai tersebut didapatkan keuntungan proyek yaitu sebesar Rp 425.538.324,00.

\section{Referensi}

Abma, V. (2016). Analisis Pengendalian Waktu Dengan Earned Value Pada Proyek Pembangunan Hotel Fave Kotabaru Yogyakarta. Teknisia, 21(2), 218-228.

Bakhtiyar, A., Soehardjono, A., \& Hasyim, M. H. (2012). Analisis faktor-faktor yang mempengaruhi keterlambatan proyek konstruksi pembangunan gedung di kota lamongan. Rekayasa Teknik Sipil, 6(1), 55-66.

Ismael, I. (2013). Proyek Konstruksi Gedung Faktor Penyebab dan Pencegahannya. Jurnal Momentum, 14(1), 46-56.

Kartikasari, D. (2014). Pengendalian Biaya Dan Waktu Dengan Metode Earned Value (Studi Kasus : Proyek Struktur dan Arsitektur Production Hall-02 Pandaan). Extrapolasi: Jurnal Teknik Sipil, 7(2), 107-114.

Khinasih, A. P. (2018). Evaluasi Waktu Dan Biaya Dengan Metoda Crashing Pada Proyek Pembangunan Rumah Sakit UII (Time and Cost Evaluation Using Crashing Method on Uii Hospital Construction Project). Universitas Islam Indonesia.

Messah, Y. A., Lona, L. H. P., \& Sina, D. A. T. (2013). Pengendalian waktu dan biaya pekerjaan konstruksi sebagai dampak dari perubahan desain (Studi Kasus Embung Irigasi Oenaem, Kecamatan Biboki Selatan, Kabupaten). Jurnal Teknilk Sipil, Universitas Nusa Cendana Kupang, 2(2), 121-132.

Milah, S. (2020). Analisis Pengendalian Waktu Proyek Konstruksi menggunakan Earned Value Concept (EVC) dan Critical Path Method (CPM) (Studi Kasus : Lanjutan Pembangunan Jalan Ruas Jalan Ciawi Singaparna Kabupaten Tasikmalaya). Jurnal Ilmiah Teknik Sipil, 1(1).

Nurdiana, A. (2015). Analisis Biaya Tidak Langsung Pada Proyek Pembangunan Best Western Star Hotel \& Star Apartement Semarang. Teknik: Jurnal Ilmiah Bidang Ilmu Kerekayasaan, 36(2), 105-109. https://doi.org/10.14710/teknik.v36i2.8906

Nuswantoro, W., Gawei, A. B. P., \& Wiwinto. (2019). Studi Praktik Estimasi Biaya Tidak Langsung Pada Proyek Konstruksi Oleh Kontraktor Di Kota Palangka Raya. Seminar Nasional Inovasi, Teknologi Dan Aplikasi (SeNITiA), 124-132. Bengkulu.

Pertiwi, A. E. (2018). Evaluasi Pengendalian Waktu Pada Proyek Pembangunan Gedung Rawat Inap 3 Dan 4 Rsud Suradadi Menggunakan Earned Value Concept (the Evaluation of Time Control on the Development Project of Inpatient Building 3 and 4 in Hospital Suradadi Using Earned Value $C$. Universitas Islam Indonesia.

Rahman, I. (2010). Earned Value Analysis Terhadap Biaya Pada Proyek Pembangunan Gedung (Studi Kasus Proyek Pembangunan Gedung C Fakultas Mipa UNS). Universitas Sebelas Maret.

Suherman, S. (2016). Pengendalian Waktu Proyek dengan Menggunakan Metode Critical Chain Project Management (Ccpm) (Studi Kasus: Pembangunan Jalan SMK IT Payakumbuh). Jurnal Teknik Industri: Jurnal Hasil Penelitian Dan Karya Ilmiah Dalam Bidang Teknik Industri, 2(2), 103-111.

Tristania, A., \& Nursin, A. (2019). Tinjauan Pengendalian Waktu Pekerjaan Jembatan Anak CBL Pada Proyek Jalan Tol Cibitung-Cilincing Seksi II. Prosiding Seminar Nasional Teknik Sipil, 639647.

Walean, D. M., Mandagi, R. J. M., Tjakra, J., \& Malingkas, G. Y. (2012). Perencanaan dan Pengendalian Jadwal dengan Menggunakan Microsoft Project 2010 (Studi Kasus: Proyek PT. Trakindo Utama). Jurnal Sipil Statik, 1(1), 22-26.

Yusdiana, E. D., \& Satyawisudarini, I. (2018). Penerapan Metode Pert Dan Cpm Dalam Pelaksanaan Proyek Pembangunan Jalan Paving Untuk Mencapai Efektivitas Waktu Penyelesaian Proyek. Jurnal Manajemen Dan Bisnis (Almana), 2(3), 20-30. 


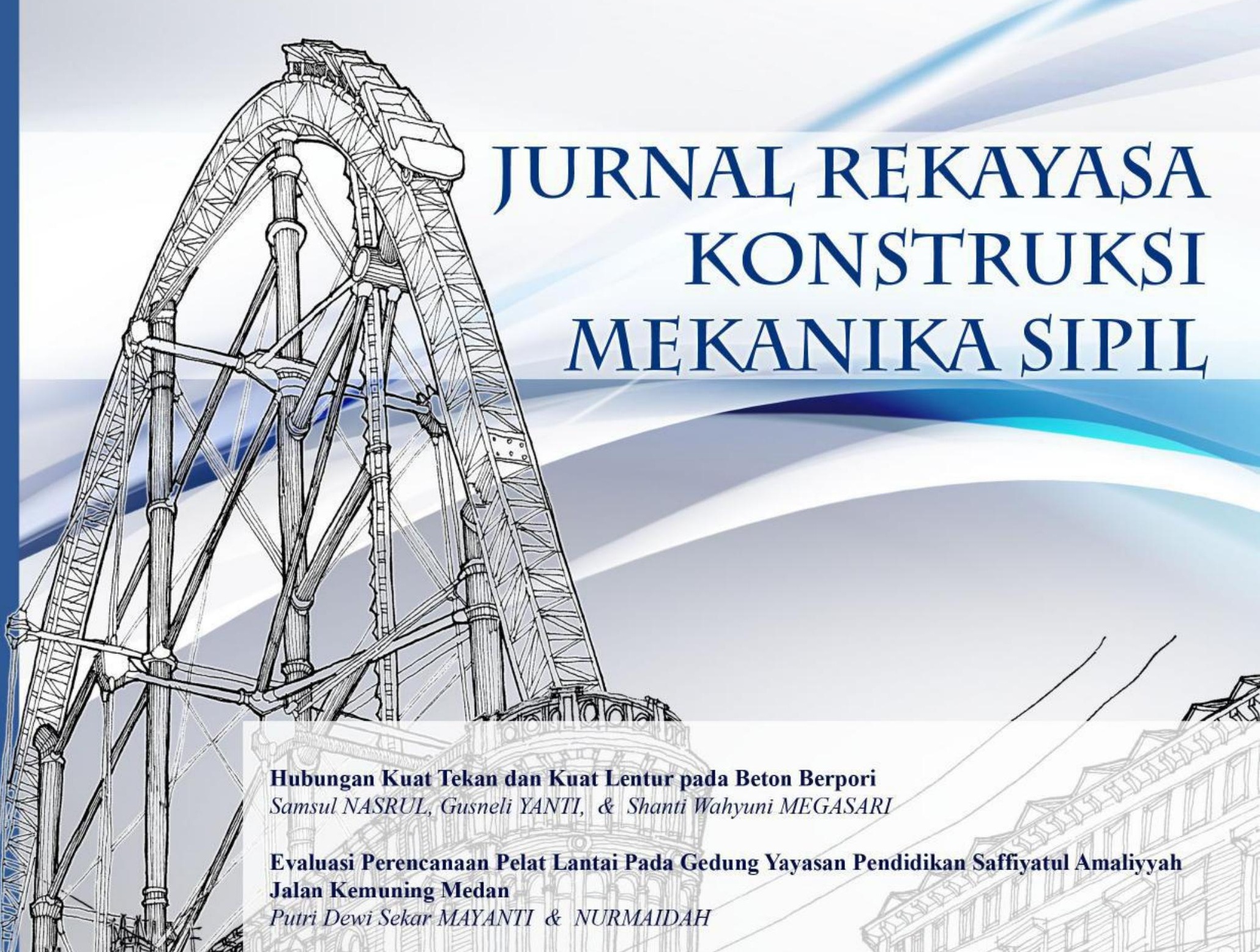

Studi Perencanaan Pondasi Sumuran Pada Pembangunan Gedung Bertingkat Tinggi (Perbandingan Antara Pondasi Tiang Pancang dan Pondasi Sumuran)

Soaloon Prima SIMALANGO, Agus PURBA, \& Kasimir SAWITO

Keinginan Menggunakan Angkot di kota Medan dengan Peningkatan Layanan Informasi Reynaldo SIAHAAN \& TOMmy Iswan LASE

Pengendalian Biaya dan Waktu dengan Metode Earned Value (Studi Kasus: Rancang dan Bangun Sistem Penyediaan Air Minum Kota Dumai 450 LPD Tahap 1A)

Edhi Pandu SUKMONO, ZAINURI, \& Widya APRIANI

Estimasi Besarnya Biaya Proyek Akibat terjadinya Rework pada Pekerjaan Finishing Ni Kadek Sri Ebtha YUNI

Pelaksanaan Manajemen Keselamatan Dan Kesehatan Kerja (SMK3) Pada Proyek Kontruksi, Studi Kasus di Kota Jakarta

Edison Hatoguan MANURUNG, Kasimir SAWITO, \& Isni Rizky YUSHADI

Fakultas Teknik Universitas Katolik Santo Thomas JI. Setia Budi No. 479-F Tanjung Sari, Medan 


\section{Jurnal Rekayasa Konstruksi Mekanika Sipil (JRKMS)}

Jurnal Rekayasa Konstruksi Mekanika Sipil (JRKMS) diterbitkan oleh Fakultas Teknik Universitas Katolik Santo Thomas. JRKMS berisi artikel-artikel ilmiah yang meliputi kajian di bidang Teknik khususnya Teknik Sipil seperti Matematika teknik, Mekanika teknik, Analisis struktur, Konstruksi baja, Konstruksi beton, Konstruksi kayu, Konstruksi gelas, Mekanika tanah, Teknik Pondasi, Hidrologi, Hidrolika, Bangunan air, Manajemen konstruksi, Dinamika Struktur, Earthquake Engineering, Informatika, Ilmu Ukur Tanah, Struktur bangunan sipil, Rekayasa Jalan Raya, serta penelitian-penelitian lain yang terkait dengan bidang-bidang tersebut.

Terbit dalam 2 (dua) kali setahun yaitu pada bulan April dan September

\section{Penasihat :}

Prof. Dr. Drs. Sihol Situngkir, MBA. (Rektor Universitas Katolik Santo Thomas)

\section{Ketua Penyunting (Editor in Chief) :}

Ir. Oloan Sitohang, M.T. (Universitas Katolik Santo Thomas)

Manajer Jurnal (Managing Editor):

Reynaldo, S.T., M.Eng. (Universitas Katolik Santo Thomas)

\section{Anggota Penyunting (Editorial Board):}

Medis Sejahtera Surbakti, S.T, M.T., Ph.D. (Universitas Sumatera Utara)

Dr. Janner Simarmata (Universitas Negri Medan)

Ir. Martius Ginting, M.T. (Universitas Katolik Santo Thomas)

Samsuardi Batubara, S.T., M.T. (Universitas Katolik Santo Thomas)

\section{Mitra Bestari (Peer Reviewer):}

Dr.Eng. Aleksander Purba (Universitas Lampung, Indonesia)

Ir. Binsar Silitonga, M.T. (Universitas Katolik Santo Thomas, Indonesia)

Ir. Charles Sitindaon, M.T. (Universitas Katolik Santo Thomas, Indonesia)

Dr. Erica Elice Uy (De La Salle University, Philippines)

Dr. Harijanto Setiawan (Universitas Atma Jaya Yogyakarta, Indonesia)

Dr.Eng. Jeffry Swingly Frans Sumarauw (Universitas Sam Ratulangi, Indonesia)

Prof. Dr-Ing. Johannes Tarigan (Universitas Sumatera Utara, Indonesia)

Linda Prasetyorini (Universitas Brawijaya, Malang, Indonesia)

Dr.Eng. Mia Wimala (Universitas Katolik Parahyangan, Indonesia)

Dr.Eng. Minson Simatupang (Universitas Halu Oleo, Indonesia)

Dr. Mochamad Raditya Pradana (Keppel Marine and Deepwater Technology, Singapura)

Dr. Senot Sangadji (Universitas Sebelas Maret, Indonesia)

Ir. Simon Dertha, M.T. (Universitas Katolik Santo Thomas, Indonesia)

Dr. Thi Nguyên Cao (Tien Giang University, Viet Nam)

\section{Ilustrator Sampul:}

Yulianto, ST., M.Eng

\section{Penerbit \& Alamat Redaksi:}

Fakultas Teknik Universitas Katolik Santo Thomas

J1. Setiabudi No. 479-F Tanjung Sari, Medan 20132

Telp. (061) 8210161 Fax : (061) 8213269

email : unika.sipil@yahoo.com 


\section{Konten}

REKAYASA STRUKTUR

hal.

Hubungan Kuat Tekan dan Kuat Lentur pada Beton Berpori

Samsul NASRUL, Gusneli YANTI, \& Shanti Wahyuni MEGASARI

Evaluasi Perencanaan Pelat Lantai Pada Gedung Yayasan Pendidikan

Saffiyatul Amaliyyah Jalan Kemuning Medan

Putri Dewi Sekar MAYANTI \& NURMAIDAH

REKAYASA GEOTEKNIK

Studi Perencanaan Pondasi Sumuran Pada Pembangunan Gedung

Bertingkat Tinggi (Perbandingan Antara Pondasi Tiang Pancang dan

Pondasi Sumuran)

Soaloon Prima SIMALANGO, Agus PURBA, \& Kasimir SAWITO

REKAYASA TRANSPORTASI

Keinginan Menggunakan Angkot di kota Medan dengan Peningkatan

Layanan Informasi

Reynaldo SIAHAAN \& Tommy Iswan LASE

MANAJEMEN KONSTRUKSI

Pengendalian Biaya dan Waktu dengan Metode Earned Value (Studi Kasus:

Rancang dan Bangun Sistem Penyediaan Air Minum Kota Dumai 450 LPD

Tahap 1A)

Edhi Pandu SUKMONO, ZAINURI, \& Widya APRIANI

Estimasi Besarnya Biaya Proyek Akibat terjadinya Rework pada Pekerjaan

Finishing

Ni Kadek Sri Ebtha YUNI

Keselamatan dan Kesehatan KerJa

Pelaksanaan Manajemen Keselamatan Dan Kesehatan Kerja (SMK3) Pada

Edison Hatoguan MANURUNG, Kasimir SAWITO, \& Isni Rizky YUSHADI 


\section{Pengantar Redaksi}

Puji dan syukur kami sampaikan kepada Tuhan Yang Maha Esa karena atas rahmatNya kami dapat menyelesaikan penerbitan Jurnal Rekayasa Konstruksi Mekanika Sipil (JRKMS) Volume 4 Nomor 1, di bulan Mei tahun 2021 ini. Jurnal ini fokus pada beragam subbidang dalam Teknik Sipil antara lain Rekayasa Struktur, Rekayasa Geoteknik, Rekayasa Transportasi, Teknik Sumber Daya Air, dan Manajemen Konstruksi. Namun, tidak menutup kesempatan bagi subbidang lainnya yang berkaitan dengan keilmuan Teknik Sipil.

Memasuki tahun ke-2 dalam kondisi pandemi COVID-19, keterbatasan dalam melakukan penelitian tidak menurunkan produktivitas kita dalam meneliti serta mempublikasikannya. Penelitian tetap harus dijalankan dan produktivitas peneliti di Indonesia masih harus terus berkembang. Dalam edisi ini, terdapat 7 artikel yang terdiri atas dua (2) artikel dalam topik Rekayasa Struktur, satu (1) artikel dalam topik Rekayasa geoteknik, satu (1) artikel dalam topik Rekayasa Transportasi, dua (2) artikel dalam topik Manajemen Konstruksi, dan satu (1) artikel dalam topik Keselamatan dan Kesehatan Kerja (K3). Redaksi memiliki kerinduan agar semakin banyak peneliti yang menerbitkan karya berkualitasnya di JRKMS untuk mendukung pengembangan wawasan dalam dunia teknik sipil. Apresiasi kami berikan kepada penulis yang tulisannya diterbitkan pada Volume 04 Nomor 01 Mei 2021 ini karena telah menginvestasikan waktu dalam menuangkan ide dan merespon masukan dari mitra bestari hingga karyanya siap untuk diterbitkan.

Sebagai penutup, yang menjadi harapan tim editorial adalah semoga jurnal ini dapat menjadi media ilmiah yang berguna bagi civitas akademika, dan perkembangan ilmu pengetahuan serta penelitian di bidang ilmu ketekniksipilan di Indonesia. Salam hangat. Salam sehat.

Mei 2021

Tim Editorial 
JURNAL REKAYASA KONSTRUKSI MEKANIKA SIPIL | Volume 4 | Nomor 1 | Mei 2021| Jurnal IImiahTeknik Sipil Fakultas Teknik Universitas Katolik Santo Thomas ejournal.ust.ac.id/index.php/JRKMS

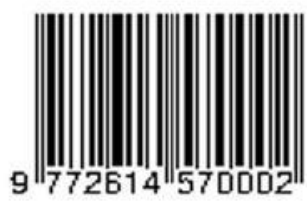

Google RaARUDA ISJDNeo : : neliti Donesearch PBASE 